\title{
El mutualismo en el mundo del trabajo (Tucumán, Argentina, 1877-1914)*
}

\section{The mutualism in the world of work \\ (Tucumán, Argentina, 1877-1914)}

\author{
VANESA TEITELBAUM \\ Instituto Superior de Estudios Sociales \\ Consejo Nacional de Investigaciones Científicas y Técnicas (CONICET) \\ Universidad Nacional de Tucumán \\ Av. Rivadavia 1917. C1033AAJ. CABA. República Argentina \\ vteitel@yahoo.com
}

\begin{abstract}
RESUMEN El artículo se propone reconstruir y analizar algunas prácticas desarrolladas por las sociedades de socorro mutuo de trabajadores formadas en Tucumán durante el último tercio del siglo XIX y, en especial, desde finales de la década de 1880. Comienza con una breve descripción en torno a las características de las mutuales, retomando algunos de los señalamientos realizados por la historia social y del movimiento obrero. Posteriormente, se examinan los objetivos y las actividades seguidas por las principales asociaciones de ayuda mutua de trabajadores que se conformaron en la ciudad de San Miguel de Tucumán y en el interior de la provincia durante los años bajo estudio. El estudio incluye también una revisión de los conflictos que se suscitaron en torno a asuntos centrales de la vida asociativa, tales como el manejo de fondos, campo hasta ahora no explorado por la historiografía sobre el tema para el periodo y el espacio elegido en esta investigación.
\end{abstract}

Palabras clave asociaciones mutuales, trabajadores, conflictos

* Artigo recebido em: 28/10/2010. Aprovado em: 04/08/2011. 
ABSTRACT The purpose of this paper is to reconstruct and analyze some practices developed by the mutual aid societies of workers formed in Tucumán during the last third of the nineteenth century and especially since late 1880. It begins with a brief description about the characteristics of mutual institutions, taking up some of the remarks made by social history and the labor movement. Subsequently, we examine the goals and activities pursued by the major associations of mutual aid workers who were formed in the city of San Miguel de Tucuman and the interior of the province during the years under study. The study also includes a review of the conflicts that arose around central issues of associative life, such as fund management, field hitherto unexplored by historians on the subject for the time and place chosen for this research.

Keywords mutual associations, workers, conflicts

\section{Introducción}

En sintonía con los procesos desarrollados en otras latitudes argentinas y latinoamericanas, desde el último tercio del siglo XIX y, en especial, a partir de finales de la década de 1880 y comienzos de los años de 1890, los trabajadores de Tucumán formaron sociedades de ayuda mutua que buscaban socorrer a sus miembros frente a las necesidades y contingencias de la vida. Algunas mutuales estaban integradas por trabajadores de un mismo oficio; otras reunían a los socios a partir de la denominación generalizada de "obreros" y, por lo general, las asociaciones de socorro mutuo incluyeron, además de trabajadores, a pequeños propietarios y empresarios bajo la figura de socios honorarios o protectores.

Siguiendo los lineamientos establecidos por el Código Civil de 1871, los dirigentes de estas asociaciones solicitaron la personería jurídica al Estado y para ello presentaron sus reglamentos, detallando además el capital y los bienes que poseían. Una vez aprobada su solicitud, las mutuales gozaban del reconocimiento oficial como asociaciones civiles y podían concretar diversas tareas en el espacio público: disponer de fondos en el banco, alquilar o comprar un local, solicitar apoyos financieros del gobierno, etc.

Tal como era lo usual en este tipo de asociación, las mutuales funcionaban mediante el pago por parte de sus asociados de cuotas de ingreso y de mensualidades, con lo cual se formaba un fondo común destinado a cubrir las ayudas y socorros a los trabajadores. ${ }^{1}$ Principalmente, las mutuales se

1 Existe una abundante bibliografía sobre las sociedades mutuales de trabajadores. A los fines de este trabajo, nos apoyamos especialmente en los estudios de RECALDE, Héctor. Beneficencia, asistencialismo estatal y previsión social/1. Buenos Aires: Centro Editor de América Latina, 1991; DI STEFANO, Roberto. 1776-1860. In: DI STEFANO, Roberto; SABATO, Hilda; ROMERO, Luis Alberto y MORENO, José Luis. De las cofradías a las organizaciones de la sociedad civil. Historia de la iniciativa asociativa en Argentina, 1776-1990. Buenos Aires: Edilab Editora, 2002, p.23-97 (Idea y coordinación Elba Luna y Elida Cecconi); SABATO, Hilda. 1860-1920, Estado y sociedad civil. 
ocupaban de la atención de la salud y la cobertura ante el fallecimiento de un socio, para lo cual la asociación preveía un monto específico destinado a solventar los gastos del sepelio y, en la mayoría de los casos, de una suma determinada para ayudar a la viuda, huérfanos y familiares cercanos del socio fallecido. ${ }^{2}$ Además, algunas sociedades incluyeron dentro de los socorros previstos los casos de desempleo y la situación de los trabajadores ambulantes. De esta forma, las mutuales podían contribuir al mejoramiento de las condiciones de vida de los trabajadores mediante el estímulo de una de sus aristas fundamentales: el trabajo. Las asociaciones de socorro mutuo se ocuparon de otros aspectos centrales dentro del universo laboral, al impulsar la sociabilidad, la educación y la cultura de los trabajadores. En ese terreno, una de las consignas prioritarias de las mutuales, particularmente de aquellas que habían alcanzado un cierto crecimiento y desarrollo, consistió en fomentar la instrucción y la lectura mediante proyectos de creación de bibliotecas y de periódicos. En suma, si bien la ayuda mutua destinada a proteger y auxiliar a los trabajadores ante la enfermedad, la muerte y, en algunos casos, frente a la falta de trabajo, fue el objeto principal de las mutuales, varias de ellas funcionaron también como asociaciones sociales, culturales, educativas y recreativas. ${ }^{3}$

Sin ánimo de agotar el tema, en las páginas que siguen trataremos de avanzar en el análisis del mutualismo en el mundo del trabajo tucumano. El artículo comienza con una breve descripción en torno a las características de las sociedades mutuales, retomando algunos de los señalamientos realizados sobre el tema por la historia social y del movimiento obrero. Posteriormente el análisis se centra en los objetivos y las actividades seguidas por las asociaciones de ayuda mutua de trabajadores que se conformaron en la ciudad de San Miguel de Tucumán y en el interior de la provincia durante los años bajo estudio. El artículo incluye también una primera revisión sobre los conflictos que se suscitaron en torno a tópicos centrales de la vida asociativa, campo hasta ahora no explorado por la historiografía sobre Tucumán para el periodo elegido, indagando los enfrentamientos y las disputas originadas a raíz de acusaciones frente a malversación de fondos que, en algunos casos, desembocaron en procesos judiciales.

In: DI STEFANO, Roberto; SABATO, Hilda; ROMERO, Luis Alberto y MORENO, José Luis. De las cofradías a las organizaciones de la sociedad civil, p.99-167. Asimismo, fueron sugerentes los análisis sobre el tema para otras latitudes. En particular: KOCKA, Jürgen. Los artesanos, los trabajadores y el Estado: hacia una historia social de los comienzos del movimiento obrero alemán. Historia Social, n.12, p.101-118, Invierno 1992; AIZPURU, Mikel y RIVERA, Antonio. Manual de historia social del trabajo. Madrid: Siglo XXI, 1994.

2 Al respecto, remitimos a una primera aproximación al tema del mutualismo entre los trabajadores plasmada en BRAVO, María Celia y TEITELBAUM, Vanesa. El asociacionismo obrero mutualista y las sociedades de resistencia. Tucumán 1890-1912, ponencia presentada en las XII Jornadas Inter/escuelas Departamentos de Historia, San Carlos de Bariloche, 28 al 31 de octubre de 2009.

3 Al respecto, fueron esclarecedores los señalamientos de KOCKA, Jürgen. Los artesanos, los trabajadores y el Estado, p.101-102 sobre Alemania y, para Argentina, los de SABATO, Hilda. 1860-1920, Estado y sociedad civil. In: DI STEFANO, Roberto; SABATO, Hilda; ROMERO, Luis Alberto y MORENO, José Luis. De las cofradías a las organizaciones de la sociedad civil, p.109. 


\section{Las mutuales y el movimiento obrero: algunas breves conside- raciones}

Tal como lo ha señalado la literatura sobre el tema, las sociedades de socorro mutuo podían revestir un "carecer puro", es decir, albergar solamente a trabajadores o un "carácter mixto", al reunir trabajadores con empresarios y otros grupos sociales. ${ }^{4}$ En todo caso, y a diferencia de las sociedades gremiales y de resistencia, las sociedades de ayuda mutua, lejos de definirse por un contenido de clase, podían albergar en su interior a trabajadores, ya sea aquellos que laboraban por cuenta propia como a los que trabajaban en relación de dependencia, junto con patrones y/o propietarios de determinado sector. ${ }^{5}$

También, es sabido que las mutuales se caracterizaban por un propósito básicamente defensivo, en tanto buscaban auxiliar a sus miembros ante las necesidades y contingencias de la vida. Otro rasgo típico de las sociedades de ayuda mutua era el apoyo y promoción que podían recibir por parte del gobierno a través de subsidios y donaciones, así como la participación de sectores propietarios y miembros de los grupos acomodados en carácter de socios honorarios y/o protectores.

Estas características de las mutuales: su propósito defensivo, el apoyo de las autoridades y en especial la falta de una definición de clase les otorgaban, según la mirada de dirigentes obreros y de militantes del periodo estudiado, menor eficacia a la hora de la protesta. En definitiva, se trataba de instituciones apoyadas y/o promovidas por el Estado que supuestamente poco tenían que ver con los intereses y las demandas de los trabajadores. Percibidas con desconfianza por parte de militantes y líderes obreros del socialismo y, en especial, del anarquismo, las impugnaciones en torno a la las prácticas mutuales, entendidas como instancias por lo general adversas a la lucha obrera, se trasladaron a su vez a los estudios sobre el movimiento obrero que relegaron mayoritariamente en sus análisis el estudio de las mutuales.

Sin embargo, una renovada historiografía social y política contribuyó a modificar las concepciones sobre las mutuales en la vida de los trabajadores, en especial, al situar la experiencia mutualista como una faceta inicial pero no menos importante en los procesos de conformación del movimiento obrero. Sin desconocer las características específicas de las sociedades de socorro mutuo, tales como su carácter de autodefensa, su necesaria vinculación

4 Tomamos las consideraciones planteadas para el caso europeo por AIZPURU, Mikel y RIVERA, Antonio. Manual de historia social del trabajo, p.152-153.

5 Al respecto, resultaron esclarecedores los comentarios de Hilda Sabato, quien sostiene que "a diferencia de las organizaciones gremiales posteriores, las de ayuda mutua no se definían en términos clasistas e incluían en su seno no solamente a trabajadores en relación de dependencia sino también a quienes lo hacían por cuenta propia e incluso a patrones o empresarios del sector correspondiente". SABATO, Hilda. 1860-1920, Estado y sociedad civil, p.115. 
con el Estado, el respaldo que podían recibir por parte del gobierno, así como la falta de una definición de clase en las mutuales, los nuevos estudios buscaron analizar otros aspectos y problemáticas relacionadas con la vida asociativa en el mundo del trabajo. Además, intentaron revalorizar los atributos inherentes a las mutualidades, destacando su potencialidad para conformar prácticas, identidades y culturas obreras. De esta manera, y en contraste con las miradas tradicionales sobre el tema, concibieron el rasgo defensivo de las mutuales y la ausencia de enfrentamientos de clase como instancias inherentes de las prácticas obreras. Asimismo, subrayaron el valor de las sociedades de ayuda mutua como ámbitos capaces de fomentar la solidaridad y la autonomía de los trabajadores, tal como sostienen Mikel Aizpuru y Antonio Rivera en su análisis sobre el tema para Europa. ${ }^{6}$

Siguiendo también a estos autores, es factible pensar que el mutualismo, especialmente el de fin de siglo, "contribuyó al intento de creación de un espacio social propio de los trabajadores". Y, por ejemplo, "la disciplina necesaria para proteger los fondos de la sociedad y la resolución de los casos conflictivos supuso un fuerte esfuerzo de autoorganización, imitado luego por otras sociedades". Gradualmente, y con el crecimiento de las sociedades gremiales y de resistencia, al influjo del avance de las corrientes vinculadas al socialismo y el anarquismo, las sociedades de socorro mutuo no desaparecieron, aunque muchas de ellas combinaron los fines tradicionales de ayuda mutua con objetivos sindicales. ${ }^{7}$

Desde una perspectiva similar, en nuestro trabajo podemos sugerir que las funciones de socorro mutuo, sumadas a las actividades de sociabilidad, educación y recreación que organizaron las sociedades de ayuda mutua desempeñaron, probablemente, un papel clave en la conformación de experiencias e identidades entre los asociados. Así, por ejemplo, tiene sentido suponer que las diversas tareas emprendidas para desarrollar la ayuda mutua entre sus asociados, así como las discusiones y decisiones acordadas en torno a diversos asuntos de la vida asociativa - elaboración y reforma de reglamentos y estatutos, inversión de los fondos económicos, incorporación de socios, organización de actividades culturales, sociales o recreativas, etc. - contribuyeron a estimular y difundir valores, hábitos y conductas relacionadas con la influencia concedida a la solidaridad, el civismo, la autonomía, el ahorro, entre otros.

6 Así, estos autores señalan: "Las actuaciones obreras no suponen necesariamente la confrontación con sus oponentes. Las experiencias mutualistas constituyeron, en ocasiones, expresiones de espacios vitales o defensivos en paralelo o al margen (aunque no siempre) de los dictados del mundo burgués. La importancia de estas sociedades fue de primer orden en la configuración de espacios de sociabilidad y de comportamientos cada vez más autónomos por parte de los trabajadores". AIZPURU, Mikel y RIVERA, Antonio. Manual de historia social del trabajo, p.148

7 En tal sentido, "en muchos estatutos se planteó la posibilidad de crear servicios que contribuyesen a la emancipación obrera, socorro de paro, educación, diversiones lícitas y hasta caja de resistencia, con lo cual se reconcilió la actividad de socorro con la solidaridad obrera revolucionaria." AIZPURU, Mikel y RIVERA, Antonio. Manual de historia social del trabajo, p.153-154. 
Por otro lado, es factible proponer, a modo de hipótesis, que en este periodo, cuando los poderes públicos no contemplaban enérgicamente la atención de la cuestión laboral, estas asociaciones surgidas en el seno de la sociedad civil contribuyeron a que los trabajadores, al menos un sector específico dentro del mundo del trabajo que podía acceder al pago de una cuota e integrar alguna sociedad, enfrentara con cierto éxito algunas necesidades y contingencias en su vida cotidiana.

Hacia comienzos del siglo XX y, en especial, entre 1902 y 1905, en el universo laboral tucumano adquirió vigor la formación de asociaciones gremiales y de resistencia, al influjo de la difusión de las corrientes organizadas dentro del mundo del trabajo como el socialismo y el anarquismo. ${ }^{8}$ Este proceso tuvo un impacto en las asociaciones mutuales que, si bien no desaparecieron de la escena pública, experimentaron un fuerte retroceso. En tal sentido, no resulta casual que el periodo de mayor formación de sociedades mutuales, al menos el registrado en el caso que nos ocupa, la provincia de Tucumán, corresponda a los años comprendidos entre 1877 y 1899.

Pero si es indudable que la primera década del siglo XX se caracterizó por el mayor crecimiento de las sociedades gremiales y de resistencia, también es cierto que las mutuales continuaron funcionando como un espacio central de la vida de los trabajadores. Algunas mutuales, como la de los tipógrafos, incluyeron durante esos años tareas de tipo gremial. Otros trabajadores, conformaron asociaciones que combinaban los fines mutuales con las prácticas destinadas a la defensa y lucha obrera. ${ }^{9} \mathrm{~A}$ modo ilustrativo, podemos mencionar el caso de los oficiales peluqueros que en marzo de 1902 se propusieron conformar una sociedad de socorros mutuos y de resistencia, proyecto cristalizado en el mes de octubre con la creación definitiva de una asociación que reunía en su interior a oficiales y patrones con la consigna central de luchar por la defensa de sus intereses comunes. ${ }^{10}$

\section{La Sociedad Argentina de Socorros Mutuos de Obreros}

A continuación, me voy a referir a una de las sociedades de socorro mutuo más destacadas dentro del mundo del trabajo tucumano entre finales del siglo XIX y comienzos del XX: la Sociedad Argentina de Socorros Mutuos

8 En esa dirección, y aunque este tema escapa ya a los fines que nos propusimos en este trabajo, quisiera señalar que, por ejemplo, durante esos años los oficiales peluqueros, los cocheros, los mozos de hoteles y confiterías, los carpinteros y los herreros constituyeron sus gremios. Asimismo, en ese periodo se crearon las sociedades gremiales de albañiles y anexos, así como la de sastres, las cuales se reorganizaron al poco tiempo como sociedades de resistencia. También, para entonces, se estableció la asociación gremial de panaderos, reemplazando al parecer a la Sociedad Protectora de Socorros Mutuos de Panaderos, primera mutual de oficio que conformaron los trabajadores en Tucumán, y sobre la cual nos referiremos un poco más adelante en este trabajo.

9 Esto se señaló en BRAVO, María Celia y TEITELBAUM, Vanesa. El asociacionismo obrero mutualista y las sociedades de resistencia.

10 El Orden, 5/3/1902. 
de Obreros, creada en 1877 con el propósito de "ofrecer a sus asociados esmerada atención en la salud de cada uno, como también cultivar las buenas relaciones y armonizar las que deben existir entre personas sociables de un pueblo culto". ${ }^{11}$ Esta asociación que en sus inicios era pequeña y no contaba con un local propio llegó a ser con el tiempo una de las más desarrolladas e importantes de la época. Un testimonio de su influencia se reveló, por ejemplo, en una nota publicada por La ilustración Obrera. Periódico literario de la juventud obrera, de literatura, artes e intereses generales, fuente sobre la que hasta ahora no se tenía ninguna noticia. Como narraba este periódico, en la celebración desarrollada el 25 de noviembre de 1894, fecha en que conmemoraba un nuevo aniversario de la fundación de la Sociedad Argentina de Socorros Mutuos, sus dirigentes y socios aprovecharon la ocasión para felicitar a los fundadores y al resto de los asociados por la "saludable empresa benéfica" y por el crecimiento alcanzado por esta sociedad. Como aseguraba su presidente José A. Guchea, la Sociedad Argentina llegaba, tras dieciocho años de existencia, "robusta y llena de vida". ${ }^{12}$

Tal como se infiere de los pocos números en que La ilustración Obrera se publicó, sabemos que allí colaboraron algunos destacados integrantes de la Sociedad Argentina de S.M. de Obreros. ${ }^{13}$ En ese contexto, no resulta tan sorprendente que dedicara un espacio significativo a testimoniar la importancia alcanzada por la Sociedad Argentina. Sin embargo, son numerosas las fuentes que corroboran su influencia. Por ejemplo, a través de la lectura de reglamentos y estatutos de la Sociedad Argentina, así como notas y comunicaciones entabladas entre sus dirigentes y el poder público, sabemos que la asociación contaba con un panteón propio y desplegó tareas de asistencia de la salud que revelaron, en comparación con otras mutuales obreras, un mayor desarrollo en materia de infraestructura, personal y socorros.

La consistencia lograda por la Sociedad Argentina en el encabezamiento de labores de ayuda mutua se combinaron, a su vez, con un vasto abanico de prácticas desplegadas en los espacios públicos, en donde se vinculó exitosamente con otras sociedades de trabajadores y mantuvo estrechos

11 Tucumán. Archivo Histórico de Tucumán (AHT). Sección Administrativa (SA). Año 1877, v.133.

12 Por su parte, el socio Francisco M. Carreras dirigió un discurso en donde aseguraba: "ninguno de vosotros ignoráis el objeto que nos congrega en este momento y en este recinto. Si, el objeto que nos trae es celebrar como nuestras fuerzas nos permitan el aniversario de la Sociedad Argentina de Socorros mutuos de Obreros, cuya benéfica acción se ha dejado sentir desde muchos años a esta parte en el seno de los obreros tucumanos y yo como miembro de esta asociación no puedo permanecer silenciosos ante la llegada de este día y con mis escasas palabras vengo a felicitar a mis compañeros y a exhortarlos para que continúen adelante en las arduas tareas que hemos emprendido. En nombre de los obreros que formamos parte de esta benéfica Sociedad yo os felicito socios fundadores por la feliz idea que hace algunos años bullía en vuestros cerebros y que tuviste la fuerza de voluntad suficiente para llevarla a cabo". La llustración Obrera, 23/12/1894.

13 Por ejemplo, el administrador de este periódico era Miguel J. Molina, quien en 1877 había formado parte de la comisión encargada de la reforma de los Estatutos de la Sociedad Argentina de S.M. de Obreros. Asimismo, en su redacción participaba Daniel Villagrán, activo militante y dirigente tipográfico, que en 1899 actuó como secretario de la Sociedad Argentina. 
vínculos con instituciones y personajes destacados del ambiente cultural, político e intelectual de la época. ${ }^{14}$

Muestra de su influencia fue también la gran proyección en el tiempo que alcanzó esta sociedad y el significativo número de socios con los que contaba. En ese sentido, una fecha clave fue la de junio de 1903, contexto en el cual la Sociedad Argentina engrosó el número de sus asociados al incorporar a los miembros de la entonces disuelta Sociedad de Obreros Unidos, institución que había sido fundada en 1900 y con la cual la Sociedad Argentina compartía una gran afinidad en cuanto a sus objetivos y al perfil de los socios (por ejemplo, ambas tenían por objetivo socorrer al trabajador argentino). ${ }^{15}$ Según aseguraba El Orden, principal diario de Tucumán durante la época estudiada, con esta fusión la Sociedad Argentina podía considerarse "como la primera entre las de su género, pues actualmente cuenta con no menos de 200 socios activos y un regular número de socias". Además, destacaba que en sus 27 años de existencia, la Sociedad Argentina era tal vez la única que tenía un reglamento más liberal y que presta especial cuidado en la atención de sus asociados cuando éstos necesitan su protección. ${ }^{16}$

El avance y crecimiento de la Sociedad Argentina se reflejó también en una noticia publicada por El Orden hacia finales de 1907, en donde afirmaba que la asociación había incrementado su número de asociados, al contar con 300 socios activos, y se encontraba en vías de remodelar completamente su edificio para alcanzar todas las comodidades necesarias. Para ello, la sociedad tenía previsto aprovechar el terreno de la casa que poseía entonces, el cual contaba con 17 metros de frente por 70 metros de fondo. Tal como aseguraba el diario, el nuevo edificio estaría equipado con un gran salón de actos públicos que ocuparía el cuerpo principal del local, con una biblioteca y con una sala de secretaría situada en el frente de la calle. Asimismo, el moderno edificio dispondría de departamentos internos de servicio y de galerías a los costados. Los trabajos de demolición de la casa actual y construcción de la nueva sede comenzarían en diciembre de ese mismo año, contando la sociedad para las obras proyectadas con una suma de 12.000 pesos en efectivo, base sólida en la medida que el terreno pertenecía a dicha asociación, aseguraba el diario al tiempo que relataba el entusiasmo de los socios por esta obra, "pues se trata de una sociedad benéfica en que los afiliados tienen completa seguridad de que se les proporcionará médico, botica, entierro y nicho en el panteón que ella posee, todo gratuitamente, sin los tropiezos y demoras y de acuerdo con lo que establece el reglamento". Paralelamente, El Orden explicaba que en

14 AHT. SA. Año 1899, v.248 y 255.

15 AHT. SA. Año 1903, v.29; AHT SA., Año 1901, v.267 Los Estatutos de la Sociedad "Obreros Unidos".

16 El Orden, 15/6/1903. 
tanto el costo de la edificación e instalación definitiva superaría bastante los 12.000 pesos con los que contaba la Sociedad Argentina, ésta había decidido recurrir a los poderes públicos y al crédito en demanda de auxilios. "Los poderes públicos, especialmente, están en la obligación de favorecer abiertamente asociaciones como la Argentina de Socorros Mutuos, formada en su mayoría por obreros y que presta servicios evidentes y reales a sus socios, siendo una de las que más se distingue y se conquista el aprecio público por la corrección y seriedad de sus procedimientos", exhortaba el diario en franco apoyo a la institución mutual. ${ }^{17}$

Si bien desconocemos el itinerario de estos proyectos, lo cierto fue que la Sociedad Argentina de S.M. de Obreros llegó a ocupar un lugar prominente dentro del mutualismo tucumano y gozó de un reconocido prestigio entre sus contemporáneos. Así, por ejemplo, en el contexto de las celebraciones previstas para festejar en 1910 el Centenario de la Independencia, la Sociedad Argentina, al igual que otras asociaciones de renombre en la época, tales como la Sociedad Española, la Sociedad Italiana, la Sociedad Extranjera, el Centro Católico de Obreros y la Unión Tipográfica que organizaban fiestas para conmemorar la Revolución de Mayo, preparó un programa para los festejos conmemorativos que tendrían lugar en su local, los cuales incluían kermes, velada literario-musical y un gran baile social. Dichos números, a excepción del baile que requería del pago de una tarjeta, serían de entrada gratuita y se invitaba especialmente a la clase obrera. ${ }^{18}$

Al momento de efectuarse el III Censo Nacional de 1914, la Sociedad Argentina contaba con un total de 410 asociados, de los cuales 319 eran varones y 91 mujeres; disponía de un capital social de 46.966 pesos m/n; había distribuido 5.879 socorros y acordado 785 pensiones. ${ }^{19}$ No era una información menor la aportada por el Censo en torno a la clasificación como obreros y la nacionalidad argentina de la mayoría de los socios de esta sociedad. En ese sentido, interesa anotar que las otras mutuales que figuraban en el Censo eran, en orden de antigüedad, la Sociedad Extranjera de S.M., creada en 1868, compuesta por un total de 46 socios, en su mayoría comerciantes, de nacionalidad italiana y con un capital social de 30.500 pesos m/n; la Española, fundada en 1878 (un año después de la Sociedad Argentina de S.M. de Obreros, la cual, como ya se dijo, fue establecida en 1877), con un capital social de 205.260 pesos m/n, 1.325 asociados, entre comerciantes, artesanos y oficiales de nacionalidad argentina y española y 1.568 pensiones acordadas. En 1878, también, se fundó la Sociedad Italiana, con 680 asociados (mayoritariamente comerciantes, artesanos y oficiales), un capital social estimado en 140.000 pesos m/n y 12.700 socorros distri-

17 El Orden, 22/10/1907.

18 El Orden, 7/5/1910.

19 III Censo Nacional de la República Argentina, 1914, v.10. Buenos Aires: Talleres Gráficos L. J. Rosso, 1916, p.288-289. 
buidos. Cinco años después se formó la Sociedad Francesa, integrada por 153 socios de profesiones varias, con un capital social de 103.000 pesos $\mathrm{m} / \mathrm{n}$ y 515 socorros distribuidos. ${ }^{20}$

\section{Mutuales de oficio}

De alcances más modestos, en cuanto al número de asociados y la disposición de recursos económicos fueron las mutuales que reunieron a los trabajadores a partir del oficio. Sin embargo, estas asociaciones de ayuda mutua realizaron importantes esfuerzos por contribuir al mejoramiento material y moral de sus miembros. En esa tónica, durante el periodo estudiado se destacaron las sociedades de panaderos y la de tipógrafos.

En 1899 y siguiendo los propósitos típicos de las mutuales, se fundó la primera mutual de trabajadores por oficio en Tucumán sobre la cual tenemos noticia: la Sociedad Protectora de Socorros Mutuos de Panaderos. Interesa señalar que una de las características que distinguió a esta asociación, la cual al momento de solicitar su personería jurídica, alcanzaba la cifra de 150 asociados, consistió en contemplar explícitamente el socorro para el socio que fuera "forasteros y no tuviera existencia propia", para quien en caso de enfermedad la sociedad preveía hacerse cargo, proporcionándole "un catre de lona con colchón, dos sábanas, dos almohadas y una frazada como igualmente una habitación aseada y cómoda para la salud". ${ }^{21}$

Por su parte, en 1893, los tipógrafos fundaron la sociedad Unión Tipográfica que llegó a ser una de las sociedades de trabajadores con mayor prestigio en la época. Además de la previsión para casos de enfermedad y fallecimiento, esta sociedad incluyó el socorro ante la carencia de trabajo y la ayuda pecuniaria frente a los conflictos laborales en que se vieran involucrados sus asociados.

Si la comparamos con otras mutuales de la época, la sociedad Unión Tipográfica fue una asociación pequeña en cuanto al número de sus integrantes; por ejemplo en 1894, al momento de solicitar al Estado su personería jurídica, contaba con 40 miembros activos. ${ }^{22}$ No obstante, los tipógrafos ocuparon un lugar destacado dentro del movimiento asociativo de los trabajadores en la época y en general de las prácticas obreras durante el periodo de análisis. En ese sentido, y aunque no podemos detenernos demasiado en este tema, interesa subrayar, aunque sea brevemente, el protagonismo alcanzado por la asociación de los tipógrafos en el universo mutual, cultural, social y sindical de los trabajadores. A modo de ejemplo, podemos anotar las estrechas vinculaciones que mantuvo la sociedad

20 III Censo Nacional de la República Argentina, p.288-289.

21 AHT. SA. Año 1899, v.183.

22 AHT. SA. Año 1894, v.206. 
Unión Tipográfica con otras sociedades prestigiosas del periodo, como el Centro de Obreros Católicos y la Sociedad Argentina de Socorros Mutuos de Obreros.

También, conviene apuntar el abundante repertorio de actividades motorizadas por los tipógrafos para fomentar la educación, la sociabilidad y la cultura de sus miembros. En esos parámetros podemos situar su proyecto de fundar una biblioteca y establecer un órgano de publicidad en el que pudieran colaborar todos sus asociados y, en esa línea, desarrollar sus conocimientos intelectuales. ${ }^{23}$ Este último anhelo, al parecer, se concretó en la publicación de El Eco del Obrero. ${ }^{24}$ Respecto a la creación de la biblioteca, y a riesgo de caer en un par de digresiones, me interesa señalar que ésta fue una aspiración muy cara del movimiento obrero. Como ya ha sido advertido por la literatura sobre el tema tanto para Argentina como para otras latitudes, las distintas corrientes organizadas del mundo del trabajo, como socialistas, anarquistas, sindicalistas y más tarde comunistas, coincidían en la importancia asignada a las actividades relacionadas con la biblioteca. ${ }^{25}$

Finalmente, otra muestra del interés de la asociación de tipógrafos por estimular y fortalecer la instrucción y la cultura de sus miembros se reveló en el conjunto de las veladas y tertulias que organizó durante el periodo bajo estudio. Estos eventos, compuestos generalmente por obras de teatro, poesía y música, permitían combinar los fines dirigidos al aprovechamiento del tiempo libre de los trabajadores con propósitos de índole cultural y educativo. ${ }^{26}$

Paralelamente los tipógrafos impulsaron enérgicamente la lucha gremial, sus acciones alcanzaron notorio relieve en el espacio público y contaron con los elogios de distintos grupos sociales en la época. ${ }^{27}$ Una muestra en ese sentido se reflejó en el artículo publicado por El Orden en 1903 en el cual instaba a los trabajadores a seguir el ejemplo de los tipógrafos

iniciadores de un movimiento simpático en defensa de sus intereses. Han construido una asociación poderosa, uniendo todos los elementos del gremio, para defenderse de los abusos de sus patrones. Los tipógrafos han demostrado que son hombres conscientes y que no se someten al látigo del amo, como las

23 AHT. SA. Año 1894, vol. 206

24 Sobre la publicación de El Eco del Obrero como una iniciativa y empresa de los tipógrafos, El Orden, 4/3/1903.

25 MASES, Enrique. El tiempo libre de los trabajadores en la norpatagonia. De la cultura política, las prácticas recreativas y deportivas al disciplinamiento social 1900-1945. Quinto Sol, Instituto de Estudios Socio-HistóricosFacultad de Ciencias Humanas, Universidad Nacional de La Pampa, n.9-10, p.73-97, 2005-2006. La importancia de la biblioteca en la labor cultural de los centros obreros o populares en España es señalada por ejemplo por GUEREÑA, Jean-Louis. Hacia una historia socio-cultural de las clases populares en España (1840-1920). Historia Social, Valencia, Centro de la UNED Alzira-Valencia, Instituto de Historia Social, n.11, p.157, Otoño 1991.

26 Véase, por ejemplo, el festival obrero organizado por la sociedad Unión Tipográfica de Socorros Mutuos, el cual incluyó discursos, conferencias de propaganda obrera y un baile familiar, en El Orden, 25/09/1903 y 30/09/1903.

27 A modo ilustrativo podemos mencionar la huelga tipográfica de 1898 (El Orden, 26/4/1/1898) y las reuniones de los tipógrafos para pedir la libertad del compañero Ramón Gramajo, quien según los trabajadores había sido víctima de un error judicial y se encontraba preso en la penitenciaría desde tres años atrás. El Orden, 29/7/1900. 
bestias de carga. En adelante los patrones estarán sobre aviso y sabrán que el mal trato dado a los tipógrafos es una ofensa para todo el gremio. ${ }^{28}$

Por último, quisiera señalar que para la fecha de elaboración del III Censo Nacional de 1914, la Unión Tipográfica de S. M., estaba integrada por 30 tipógrafos de nacionalidad argentina, disponía de un capital de 6.502 pesos $\mathrm{m} / \mathrm{n}$ y de una cifra equivalente de socorros repartidos. ${ }^{29}$

\section{Centros de trabajadores en el interior de la provincia}

En el interior de la provincia funcionaban algunas sociedades mutuales de trabajadores. Para la época bajo estudio, las más importantes fueron, sin duda, el Centro de Socorros Mutuos de Aguilares y el Centro de Trabajadores de Socorros Mutuos de Monteros, ambos fundados en 1899.

Definido con un carácter cosmopolita, el Centro de Socorros Mutuos de Aguilares buscaba satisfacer los objetivos usuales de las mutuales, condensado, de acuerdo con lo estipulado por su reglamento, en la aspiración de "brindar la mejor atención posible de la salud y robustecer los vínculos de amistad y de unión". ${ }^{30}$

Para 1914, el III Censo Nacional consignaba que este centro mutual de Aguilares contaba con un capital social de 832 pesos m/n, 51 asociados de profesiones varias y nacionalidad argentina, 404 socorros distribuidos y 138 pensiones acordadas. ${ }^{31}$

Por su parte, el Centro de Trabajadores de Socorros Mutuos de Monteros se había constituido a partir de la necesidad explícita de mejorar las condiciones de vida de los artesanos. Como señalaba su presidente en la carta dirigida en al Ministro de Gobierno para solicitar la personería jurídica, "convencidos de que esa mejora no podría obtenerse sino por la unión y reglamentación de los deberes y derechos que nos acuerdan nuestras leyes, contribuyendo así a moralizar a nuestra clase obrera, para que ella sea mirada como un factor de progreso moral y social, digno de consideración y respeto, de común acuerdo hemos constituido el Centro". En su pedido, el dirigente agregaba que la sociedad había sido inaugurada el 30 de agosto de ese año de 1899, con un número de 100 socios y disponía de un local en la calle 24 de setiembre, Plaza Bernabé Aráoz números 18 y 19. ${ }^{32}$

Sin embargo, al parecer, esta solicitud no recibió una respuesta favorable, ya que reiteraron este pedido en 1902. La presentación de los Estatutos del Centro de Trabajadores de Monteros que acompañó la nueva solicitud

\footnotetext{
28 El Orden, 9/6/1903

29 III Censo Nacional de la República Argentina, p.288-289.

30 AHT. SA. Año 1899, v.255.

31 III Censo Nacional de la República Argentina, p.288-289.

32 AHT. SA. Año 1899, v.256.
} 
demostró que la asociación se encontraba en las condiciones legales para acceder a la personería jurídica. Según afirmaba el dictamen del Ministro Fiscal, se trataba de una sociedad cuyo objeto principal era el bien común y la protección recíproca de los asociados. Asimismo, se pudo comprobar, mediante los certificados adjuntados, que dicha asociación contaba con una cifra de 649.66 pesos m/n colocados en el Banco de la Nación Argentina; disponía de muebles y útiles propios y no subsistía de asignaciones del Estado. Con lo cual, le fue otorgada la personería jurídica al Centro de Trabajadores de Monteros que para entonces estaba integrado por 153 socios. ${ }^{33}$

Contar con un Reglamento o Estatutos, disponer de bienes propios y de un capital suficiente que le permitiera mantenerse sin el patrocinio del Estado eran requisitos previstos por la ley para otorgar a una asociación la personería jurídica. Además, tiene sentido sugerir que estos atributos revelaban también la consistencia de una asociación de trabajadores que a través de un patrimonio físico podía perdurar en el tiempo. En esa dirección, me gustaría sugerir - recuperando las sugerencias realizadas por historiadores sociales de otras latitudes - que la aspiración más cara de las asociaciones de trabajadores era contar con un local propio. Como señala Jean-Louis Guereña para el caso español, "es bien sabida la verdadera obsesión del movimiento obrero en lograr un espacio propio, un local específico, un patrimonio cultural" ${ }^{34}$ En una tónica semejante, Carlos Serrano sugiere la "voluntad progresiva del movimiento obrero de apartarse de los sitios donde ha nacido y de conseguir un local propio, tan necesario a su organización como a su ideología". ${ }^{35}$

A continuación, quisiera señalar, aunque sea brevemente, que de acuerdo a lo establecido en sus Estatutos, el Centro de Trabajadores de Monteros disponía para la asistencia de la salud de una estructura asociativa con cierto desarrollo, expresada por ejemplo en la actuación de dos comisarios y dos enfermeros. Los primeros recibían los avisos de enfermedad y los pedidos de socorro y visitaban a los enfermos, al menos dos veces por semana. Por su parte, los enfermeros eran los encargados de visitar a los enfermos que el comisario indicara por lo menos una vez al día, dar cuenta del estado de salud de los mismos y suministrar el subsidio pecuniario. ${ }^{36}$

33 AHT. SA. Año 1903, v.293.

34 GUEREÑA, Jean-Louis. Hacia una historia socio-cultural de las clases populares, p.157.

35 "Nacida en contacto con la cultura popular, la cultura obrera aspira apartarse de ésta y tomar sus distancias: contra la cultura dominante, la cultura obrera afirma su presencia pero frente a la cultura popular, marca sus diferencias y se instala. Rechazada y marginalizada, la cultura 'popular' vacilaba entre los bajos fondos de la mala vida y los grandes espacios de la errancia. Periódicamente, pero para un tiempo drásticamente limitado, se veía reconocido el derecho a ocupar la calle o la plaza; pero estaba claro que una vez acabado su tiempo, el carnaval recogería sus bártulos para irse con la música a otra parte. Pero el movimiento obrero repudia esta permanente provisionalidad, busca sus muebles, aspira a un hogar ya que está hecho para durar: el local, el edificio, se convierten de este modo en conquistas sobre el tiempo". In: SERRANO, Carlos. Cultura popular/cultura obrera en España alrededor de 1900. Historia Social, Valencia, Centro de la UNED Alzira-Valencia, Instituto de Historia Social, n.4, p.23-24, Primavera-Verano 1989.

36 AHT. SA. Año 1903, v.293. 
Por otra parte, y de forma semejante a lo establecido por la Unión Tipográfica, el Centro de Trabajadores de Socorros Mutuos de Monteros incluyó dentro de los socorros previstos la falta de trabajo. Para ello preveía, en la medida de lo posible, fomentar la colocación de los socios desocupados entre las empresas de sus miembros $u$ otras. ${ }^{37}$

En cuanto a lo cultural, el centro mutual de Monteros se propuso instruir por medio de la lectura a sus asociados, para lo cual proyectaba la compra de libros y la solicitud a las direcciones de diarios y periódicos de envío gratuito de sus ejemplares. ${ }^{38}$

Finalmente, interesa apuntar que para la fecha de elaboración del III Censo Nacional, el Centro de Trabajadores de Socorros Mutuos de Monteros estaba integrado por 100 socios de profesiones varias y origen argentino, contaba con un capital estimado en 1.900 pesos $\mathrm{m} / \mathrm{n}$ y había distribuido 980 socorros. ${ }^{39}$

\section{El Centro Católico de Obreros y el Centro Cosmopolita de Tra- bajadores}

En este apartado me voy a referir a dos instituciones contrapuestas ideológicamente que desempeñaron un papel fundamental en la vida de los trabajadores durante los años estudiados, el Centro Católico de Obreros y el Centro Cosmopolita de trabajadores. Si bien decidimos incluirlos en este trabajo, estos ámbitos, creados en la ciudad de San Miguel de Tucumán, traspasaron ampliamente el movimiento mutualista. Brevemente, mencionaremos también los centros católicos conformados en el interior de la provincia y las mutuales de mujeres trabajadoras.

\section{Los centros de obreros católicos}

En 1895 y al influjo del padre dominicano Ángel Boisdrón se creó el Centro Católico de Obreros siguiendo el objetivo explícito de "defender y promover el bienestar material y espiritual de la clase obrera, en marcada oposición a la funesta propaganda del socialismo y de la impiedad". ${ }^{40}$ De acuerdo con

37 AHT. SA. Año 1903, v.293.

38 AHT. SA. Año 1903, v.293.

39 III Censo Nacional de la República Argentina, p.288-289. Otra sociedad de trabajadores consignada por el III Censo Nacional fue la Sociedad Progreso, creada en 1906 en Villa Alberdi, compuesta por 50 obreros de nacionalidad argentina, un capital social estimado en 1.500 pesos $\mathrm{m} / \mathrm{n}$ y 225 socorros distribuidos, sobre la cual, lamentablemente no tenemos hasta ahora más información. También en el interior de la provincia funcionaba una asociación mutual de tipo étnica, la sociedad Umberto $1^{\circ}$, creada en la ciudad de Concepción en el año 1904, con 51 socios de profesiones varias, nacionalidad italiana, 800 pesos $\mathrm{m} / \mathrm{n}$ de capital social y 400 socorros distribuidos.

40 Este centro católico de obreros estaba íntimamente relacionado con las iniciativas que a nivel nacional se desarrollaban en numerosas provincias argentinas de acuerdo con los postulados de la encíclica Rerum Novarum y la actuación del sacerdote redentorista Federico Grote, creador de los círculos de obreros en Argentina. Un desarrollo más amplio de este tema se encuentra en BRAVO, María Celia y TEITELBAUM, Vanesa. Socialistas y católicos 
la lectura de sus Estatutos, sabemos que el Centro de Obreros Católicos de Tucumán otorgó una importancia central a los propósitos de socorro mutuo para los casos de enfermedad, la fundación de escuelas primarias para niños y la creación de clases nocturnas para adultos, el establecimiento de agencias de trabajo, la fundación de cajas de ahorro y la organización de actos festivos en el local del centro para proporcionar "recreo honesto" a los trabajadores e "ilustrar su espíritu mediante conferencias sobre temas cívicos morales y religiosos". ${ }^{41}$ Dentro de estas últimas preocupaciones, podemos situar las abundantes actividades de entretenimiento, instrucción y propaganda que organizó el Centro de Obreros Católicos, tales como paseos campestres, excursiones y fiestas que incluían por lo general la presentación de comedias morales, funciones de literatura y de música. Además, el centro impulsó numerosas conferencias para obreros encaminadas a subrayar los beneficios de la unión y el socorro mutuo, la importancia del catolicismo para la moralización de la sociedad, las formas para mejorar la situación de los artesanos, así como diversos tópicos relacionados con la "cuestión social". 42

Finalmente, interesa agregar que también en el interior de la provincia se crearon centros de obreros católicos, tales como el fundado en la ciudad de Monteros en 1899, con características semejantes al de San Miguel de Tucumán. ${ }^{43}$

Más adelante, en 1906, se estableció el Círculo de Obreros Católicos en el Ingenio Luján que ofrecía a sus miembros "médico y medicina, goce de sueldo en caso de enfermedad, seguro para los accidentes ocasionados por el trabajo, recreos honestos y fiestas en el local propio de la sociedad, y todos los medios legales para mejorar la situación económica de los obreros de los ingenios". Tal como transcribía la prensa, el Círculo de Obreros de Luján estaba "incorporado en la gran sociedad de los círculos de obreros, que fundada en el año 1892 está extendida por toda la república y cuenta ya con 56 círculos distintos, los que todos se prestan ayuda mutua y defensa". ${ }^{44}$

\section{El Centro Cosmopolita de Trabajadores}

Hacia finales de 1897 se conformó el Centro Cosmopolita de Trabajadores, "de protección mutua", con el lema "Uno para todos y todos para uno". ${ }^{45}$ Tal como quedó registrado en la carta elevada por sus dirigentes a

disputando el mundo los trabajadores. Protesta, sociabilidad y política en Tucumán (1895-1910). Entrepasados. Revista de Historia, Buenos Aires, n.35, p.67-87, comienzos de 2009.

41 Estatutos del Centro Católico de Obreros de Tucumán fundado el 2 de junio de 1895. Tucumán: Imprenta La Moderna, 1908, p.1.

42 Al respecto, El Orden, del 15/11/1897 al 2/10/1909

43 BRAVO, María Celia y TEITELBAUM, Vanesa. Socialistas y católicos disputando el mundo los trabajadores, p.67-87.

44 El Orden, 16/5/1906

45 La Vanguardia, 11/12/1897. Sobre la creación del Centro Cosmopolita de Trabajadores véase también El Orden, $3 / 11 / 1897$ y desde el 28/11/1898 al 19/11/1898 
los centros socialistas y sociedades obreras de Buenos Aires - reproducida en el órgano oficial del Partido Socialista en Argentina: La Vanguardia - el centro obrero de Tucumán se había conformado con el objeto de defender "la causa del proletariado, es decir el mejoramiento de la clase trabajadora" de acuerdo a los ideales sostenidos por los socialistas. ${ }^{46}$

De la lectura de la prensa provincial, en particular del diario El Orden, es posible inferir que el Centro Cosmopolita de Trabajadores estuvo integrado por diversos sectores provenientes del mundo del trabajo, sobre todo urbano, destacándose la presencia del segmento vinculado con el mundo de los oficios, tales como tipógrafos, panaderos, carpinteros, zapateros, sastres, cocheros, etc. Y aunque todavía quedan aspectos que explorar en cuanto a su composición, es factible sugerir que los militantes y dirigentes del centro adherían a las corrientes del anarquismo y sobre todo del socialismo. Una muestra en ese sentido, se reflejó, por ejemplo, a comienzos de 1901, cuando La Vanguardia incluyó dentro de las agrupaciones del interior del país adheridas al Partido Socialista Argentino al Centro Cosmopolita de Trabajadores de Tucumán. ${ }^{47}$

Con el propósito de estimular el mejoramiento de las condiciones de vida y de trabajo, este centro obrero se planteó entre sus proyectos, la creación de una cooperativa de consumos para obreros y el establecimiento de una escuela para niños pobres. ${ }^{48}$ Lamentablemente desconocemos el resultado que tuvieron estas propuestas que se ajustaban a los postulados del socialismo sobre la importancia de la educación y la formación de cooperativas entre los trabajadores. Sin embargo, lo que sí podemos afirmar es que al despuntar el año de 1904, y en un contexto de avance y desarrollo del Centro Cosmopolita de Trabajadores, este espacio inauguró su salón de lectura, compuesto por periódicos, libros y folletos de sociología y propaganda obrera. En esa fecha también, comenzó sus trabajos para establecer una biblioteca. ${ }^{49}$

Es factible proponer, también, que este espacio obrero se propuso articular los fines de recreación, sociabilidad y cultura con el propósito de fomentar el mejoramiento de las condiciones de vida y de trabajo. Siguiendo esas consignas, motorizó un vasto conjunto de actividades que combinaban el aprovechamiento del tiempo libre de los trabajadores con el impulso a la educación, el adelanto cultural y la conformación de una militancia e identidad obrera. En esos parámetros podemos situar las numerosas veladas y tertulias literario-musicales, llamados también festivales obreros

46 La Vanguardia, 18/06/1898

47 La Vanguardia, 5/1/1901

48 El Orden, 5/12/1901, 7/12/1901 y 10/12/1901

49 El Orden, 18/1/1904. Según el órgano de expresión del anarquismo, La Protesta Humana, la creación del salón de lectura fue una iniciativa presentada por los integrantes anarquistas del Centro Cosmopolita de Trabajadores a la Comisión Directiva. La Protesta Humana, 26/4/1902. 
de propaganda, compuestos por obras de teatro, poesías, música, baile y conferencias sobre temas de actualidad e interés obrero, entre otros. ${ }^{50}$

Asimismo, y para alcanzar el desarrollo y el adelanto de los trabajadores, el centro cosmopolita impulsó enérgicamente la asociación gremial, apoyando y coordinando la mayoría de las demandas y las protestas de los trabajadores frente a los patrones y los poderes públicos. ${ }^{51}$

Otra arista central de la actuación del Centro Cosmopolita de Trabajadores consistió en propiciar la intervención de los obreros en el terreno electoral, especialmente en las contiendas para renovar concejales en el municipio. En esa dirección, un momento clave fue el año 1901, cuando el centro convocó a los distintos gremios y asociaciones de trabajadores de Tucumán a participar de asambleas en su local para debatir candidatos y propuestas. En dichos encuentros se reunieron aproximadamente 200 trabajadores, entre sastres, zapateros, talabarteros, albañiles, etc., ${ }^{52}$ y se acordó el siguiente programa:

$1^{\circ}$ Suprimir el impuesto de piso a los repartidores y vendedores a pie $2^{\circ}$ Casas de baño para obreros

$3^{\circ}$ Higienización de casas de inquilinato y de establecimientos fabriles

$4^{\circ}$ Servicio médico gratuito y a domicilio para los pobres de la capital

$5^{\circ}$ Reglamentar el trabajo de menores de 14 años

$6^{\circ}$ Cierre de las casas de comercio los días festivos desde las 12 horas..$^{53}$

En la medida que se trataba de un programa encaminado a orientar las acciones de los candidatos propuestos por los obreros para acceder al Consejo Municipal, las demandas se referían al conjunto de la población, especialmente estaban dirigidas a beneficiar a los trabajadores y sectores populares del Municipio Capital, sin limitarse al universo acotado de los miembros de asociaciones mutuales obreras (o de otra naturaleza). Por otro lado, quisiera subrayar que los puntos planteados en este programa remitían a algunos de los principales reclamos del movimiento obrero y de las corrientes de izquierda en el mundo del trabajo durante la época bajo estudio, como el socialismo. Algunos de estos tópicos estaban presentes, además, en los proyectos de reformadores liberales y en profesionales como médicos - higienistas. Así, por ejemplo, la preocupación de los integrantes de este espacio obrero por atender aspectos concernientes a la

50 Las actividades motorizadas por el Centro Cosmopolita de Trabajadores se pueden ver en El Orden, desde noviembre de 1897 a febrero de 1905. Un desarrollo más amplio sobre las prácticas de este espacio obrero en BRAVO, María Celia y TEITELBAUM, Vanesa. Socialistas y católicos disputando el mundo los trabajadores, p.67-87 y, recientemente, TEITELBAUM, Vanesa. Trabajadores: sociabilidad, cultura y recreo en Tucumán del entre siglo. II Encuentro Internacional Teoría y práctica política en América Latina. Nuevas Derechas e izquierdas en el escenario regional, Universidad Nacional de Mar del Plata, 3, 4 y 5 de marzo de 2010. CD ROM, ISBN: 978-987-1314-96-6.

51 Un desarrollo más amplio en BRAVO, María Celia y TEITELBAUM, Vanesa. Socialistas y católicos disputando el mundo los trabajadores, p.67-87

52 El Orden, 9/3/1901 y $12 / 3 / 1901$.

53 El Orden, 29/3/1901. 
higiene pública, al cuidado de la salud y a la atención de la enfermedad, expresada en las demandas para resolver los problemas relacionados con la falta de salubridad e higiene en los espacios laborales y la dificultad de los grupos con menores recursos económicos para contar con asistencia médica, se relacionaba estrechamente con la influencia asignada a estos temas por los sectores vinculados con el reformismo liberal, el higienismo y con la tendencia que lideró las prácticas sociales, mutuales, gremiales y políticas de los trabajadores que integraban el Centro Cosmopolita: el socialismo.

\section{Mutuales de trabajadoras}

Si bien en menor escala, las mujeres trabajadoras formaron también sus propios espacios asociativos. Sujetas a los límites impuestos por la legislación que restringía la actuación de las mujeres en la vida pública, éstas formaron sociedades tuteladas por otros grupos sociales (por ejemplo asociaciones dirigidas por hombres). Tal fue el caso de la Sociedad de Socorros Mutuos de Mujeres, establecida en 1898 bajo los auspicios del Centro Cosmopolita de Trabajadores. ${ }^{54}$

Por otra parte, las mujeres crearon sociedades al amparo de una estructura jerárquica, como la perteneciente a la Iglesia católica. En esa línea, podemos mencionar, a modo ilustrativo, a la Sociedad de Obreras del Santísimo Nombre de Jesús, formada en 1900 con los fines de moralizar por medio de las prácticas religiosas a la mujer obrera, fomentando su piedad cristiana. ${ }^{55}$ Tal como relataba la prensa, esta sociedad buscaba "elevar el nivel moral de la clase proletaria y ayudarla a mejorar su situación pecuniaria proporcionándole asistencia médica, medicamentos y los elementos necesarios cuando los quebrantos de salud le impidan trabajar". ${ }^{6}$

De esta forma, podemos sugerir que la Sociedad de Obreras del Santísimo Nombre de Jesús articulaba los objetivos del socorro mutuo con los propósitos proselitistas de promover la moralidad y la religión católica en las mujeres trabajadoras. Y no resulta ocioso apuntar que esta sociedad llegó a contar con un monumento en el Cementerio Norte. Este no era un dato insignificante en la vida de las mutuales que tenían entre sus objetos prioritarios ocuparse de la cobertura ante el fallecimiento de un socio, atendiendo, por ejemplo, aspectos relacionados con la organización del funeral, los gastos del sepelio y el otorgamiento de ayudas económicas a los familiares del socio fallecido. En todo caso, y como juzgaba El Orden, dicha obra revelaba "un esfuerzo poco común si se tiene en cuenta las 
dificultades con que tropieza la escasez de recursos en la persecución de su marcha una asociación de obreras de la índole que nos ocupa". ${ }^{57}$

\section{Los conflictos en las asociaciones por el manejo de fondos}

No resulta tan sorprendente que en el transcurso del amplio periodo comprendido entre su creación en 1877 y 1914, fecha en la cual se publicó el Censo, la Sociedad Argentina de S.M. de Obreros experimentara cambios. Tal como se desprende de la documentación consultada, algunas de estas transformaciones se plasmaron en la reforma de sus Estatutos, los cuales fueron modificados en distintos momentos, como el año 1880, en 1894, en 1899 y en 1900.58 También, y como es lógico en cualquier asociación, más aún si ésta funcionó durante un tiempo prolongado, resulta comprensible que hayan surgido en su interior tensiones y conflictos. Sin duda, el más sonado fue el que tuvo lugar en 1897, cuando un fuerte enfrentamiento entre los miembros de la Comisión Directiva de la Sociedad Argentina de S. M. de Obreros desembocó en un juicio contra su presidente y su tesorero, acusados de malversación de fondos.

Del análisis de este proceso judicial se desprende que el conflicto comenzó con la donación de una suma consistente en 1.500 pesos m/n que realizó el gobernador de la provincia a la Sociedad Argentina de S.M. de Obreros para la construcción de su salón social. Según los argumentos vertidos en el juicio, el dinero había sido entregado al presidente de la sociedad, quien depositó una parte del mismo en el Banco Nación y resolvió emplear el resto para fines personales. ${ }^{59}$

Luego de una larga batalla legal, en la cual se cruzaron acusaciones, se presentaron pruebas y desfilaron varios testigos, el juez decidió absolver a los dos acusados, dejándolos en completa libertad. No obstante, interesa destacar que la dureza de las impugnaciones expresadas en el transcurso del litigio, las denuncias que se intercambiaron entre acusadores y acusados, las diversas declaraciones y el conjunto de documentación probatoria que fue presentada en este sumario alcanzaron un impacto irreversible en la vida de esta asociación. De esta forma, y más allá del resultado final del juicio, favorable a los acusados, el corolario de esta disputa fue el desprendimiento de un sector de la sociedad, en particular de aquellos miembros del directorio que habían sido objeto de las denuncias. ${ }^{60}$

Dos años después, en 1899, este grupo que se había separado de la Sociedad Argentina de S.M. de Obreros constituyó la asociación de socor-

57 El Orden, 4/4/1903.

58 A modo de ejemplo, AHT. SA. Año 1899, v.255 y Año 1900, v.261.

59 AHT. Sección Judicial Criminal (SJC). Caja 236, expediente 9, año 1897. Por defraudación a la Sociedad Argentina de Socorros Mutuos de Obreros.

60 AHT. SJC. Caja 236, expediente 9, año 1897. Por defraudación a la Sociedad Argentina de Socorros Mutuos de Obreros. 
ros mutuos denominada "Obreros de San José" que contó con aprobación eclesiástica y dirección espiritual del fraile Salvador Villalba, perteneciente a la orden de los franciscanos. ${ }^{61}$ En esa fecha, y haciendo referencia a la formación de esta asociación, el nuevo presidente de la Sociedad Argentina elevó una solicitud al gobernador de la provincia para pedirle la asignación de una pensión mensual que pudiera contribuir a la construcción de su salón social. Para reforzar su solicitud, el dirigente le informaba que la asociación había recibido del mandatario anterior una donación destinada al mismo objeto. Sin embargo, le explicaba que

hubo en ese entonces algunos malos hijos que la componían, que desconociendo un mandato expreso de nuestros Estatutos, se separaron de ella, para constituirse en mayoría y supuesta Sociedad Argentina de Socorros Mutuos de Obreros, organizando un Directorio falso, para autorizar a su Presidente recibir el dinero que estaba donado, naciendo de allí un pleito que la minoría sostuvo hasta su triunfo, como podrá acreditar su dignísimo Ministro Fiscal en ese entonces. Son estos los que para cubrir un pasado bochornoso, han fundado una nueva sociedad con el nombre de Obreros de "San José", figurando como primeras autoridades de ella y la mayoría de sus Vocales, de todos aquellos que autorizaron la malversación del mencionado donativo, sin que hasta hoy podamos conseguir la devolución del dinero con lo que se contaba para llevar a debido efecto nuestro proyecto. ${ }^{62}$

Tal como se infiere de estas palabras, más allá del fallo absolutorio, el desenlace del juicio fue interpretado como un triunfo para la Sociedad Argentina, en la medida que los miembros acusados se escindieron de la misma. Además, de acuerdo con el testimonio del presidente de la asociación, los dirigentes acusados de malversación de fondos en la justicia no conformaban autoridades legítimas y esta situación quedó aún más comprobada tras la denuncia judicial.

En cuanto al asunto particular que alentaba la solicitud, es decir, el pedido de una pensión para construir el salón social de la asociación, el dirigente de la Sociedad Argentina añadía que los gastos realizados "en nuestra defensa y la demanda hecha en nuestros socios enfermos han debilitado en sumo grado nuestros recursos de veintiún años de labor". Finalmente, el presidente apelaba al "desinteresado patriotismo", a "los relevantes méritos" y a "los buenos sentimientos humanitarios" del gobernador, agregando que al tratarse de una obra humanitaria, éste sabría atender la solicitud de la Sociedad Argentina, la cual por su parte "sabrá inmortalizar su nombre y los descendientes de ella venerarán su memoria". ${ }^{63}$

De esta forma, el dirigente de la Sociedad Argentina recurría a un vocabulario que exaltaba los rasgos de humanidad y patriotismo en el gober-

61 Sobre la sociedad de socorros mutuos Obreros de San José: AHT. SA. Año 1899, v.248 y v.249

62 AHT. SA. Año 1899, v.248.

63 AHT. SA. Año 1899, v.248. 
nador, entendiendo que éstos avalaban el apoyo a la asociación mutual, definida como una obra humanitaria. Sin duda, se trataba de un lenguaje apropiado para la relación entre los poderes públicos y las sociedades de ayuda mutua, percibidas como instituciones capaces de fomentar valores basados en la solidaridad y contribuir al desarrollo de conductas fincadas en la moral, el civismo, el ahorro, el patriotismo, etc.

Quisiera referirme ahora, aunque sea brevemente a otro juicio que involucró a las mutuales de trabajadores durante la época estudiada. Me refiero, precisamente, a la sociedad "Obreros de San José", que en 1899 se formó, como ya se dijo, a partir del desprendimiento de un sector de la Sociedad Argentina de S.M. de Obreros. Al poco tiempo de su creación, en 1901, esta nueva asociación fue objeto también de un extenso litigio judicial por malversación de fondos. En este caso, las denuncias recayeron en tres miembros de la Comisión Directiva: su presidente, el herrero Severo Blanco, su tesorero, Gregorio Suárez Mansilla, de oficio peluquero, y su secretario, el panadero Nemesio Ramírez. Un abundante expediente compuesto por las declaraciones de los acusados, las pruebas presentadas y los testimonios de los testigos, desembocó finalmente en la decisión de que los acusados eran inocentes, con lo cual fueron puestos en libertad. ${ }^{64}$

No obstante estos fallos absolutorios, lo que me interesa, en rigor, es subrayar cómo el manejo de los fondos económicos constituía uno de los aspectos más controvertidos y ríspidos de la vida asociativa. Se trataba sin lugar a dudas de un rubro sensible, capaz de promover tensiones y enfrentamientos al interior de las sociedades mutuales. Y aunque no siempre, claro está, tales conflictos podían desembocar en impugnaciones en la arena judicial como las que se expuso aquí, tiene sentido suponer que las decisiones en torno al uso de los recursos materiales constituían una de las facetas más complejas de las experiencias vividas en las asociaciones.

En tal sentido, interesa mencionar el enfrentamiento producido hacia octubre de 1904 entre los socialistas y los anarquistas que componían el Centro Cosmopolita de Trabajadores. De acuerdo con la información recabada en la prensa partidaria, sabemos que los desacuerdos se habían originado en torno al manejo de los fondos de la caja social de este centro obrero que promovió una serie de tensiones y denuncias entre los integrantes de la Comisión Directiva, especialmente entre los grupos adheridos al socialismo y los sectores afines al anarquismo, éstos últimos encargados de llevar en ese momento los asuntos económicos. ${ }^{65}$

Aunque no conocemos los detalles de cómo se resolvió finalmente este enfrentamiento, tiene sentido pensar que el mismo fue uno de los motivos

64 AHT. SJC. Caja 264, expediente 3, año 1901. Por defraudación a la Sociedad de Socorros Mutuos Obreros de San José.

65 La Vanguardia, 16/4/1904, 7/5/1904 y 22/10/1904 
centrales que alentó finalmente la disolución de este espacio obrero. Así, para marzo de 1905 no encontramos ninguna evidencia sobre la existencia del Centro Cosmopolita de Trabajadores.

Para terminar, interesa agregar que los conflictos en torno al manejo de los recursos económicos se manifestaron también al interior de sociedades gremiales y centros obreros conformados fuera de los principios del mutualismo. Si bien este tema escapa ya a los fines que nos hemos propuesto en este trabajo, quisiera señalar que en estas asociaciones los desacuerdos producidos en este rubro adquirieron estado público a través de quejas y solicitadas publicadas en la prensa. Una muestra en ese sentido se reveló, por ejemplo, en 1905 con los problemas desarrollados al interior del Centro Socialista y en 1906 con lo sucedido en la Sociedad de Resistencia de Albañiles y Anexos. ${ }^{66}$

\section{A modo de conclusión}

Dijimos en la introducción que desde el último tercio del siglo XIX y, en especial, a partir de 1890, se formaron en Tucumán sociedades de ayuda mutua que buscaban contribuir al mejoramiento moral y material de los trabajadores, resguardándolos frente a las necesidades y contingencias de la vida. Como señalábamos en el trabajo, tal como era lo usual en este tipo de asociación, sus fines primordiales consistían en prestar ayuda a sus miembros ante la enfermedad, la invalidez y el fallecimiento; además, se establecía el objetivo de propiciar la armonía y fraternidad entre los asociados.

Para recapitular y avanzar algunas consideraciones finales, me interesa sugerir, en primer lugar, que el movimiento mutualista de los trabajadores no constituyó un bloque homogéneo. Existieron asociaciones mutuales que agruparon al trabajador de nacionalidad argentina (tal fue el caso, por ejemplo de la Sociedad Argentina de S. M. de Obreros y de la Sociedad Obreros Unidos), sociedades cosmopolitas que integraron a trabajadores argentinos y extranjeros, como el Centro Cosmopolita de Trabajadores, mutuales de oficios --como la de los tipógrafos y panaderos-- y centros de socorros mutuos que reunían a los trabajadores a partir de la localidad, como los establecidos en las ciudades de Aguilares y Monteros. Hubo también mutuales de mujeres y asociaciones de ayuda mutua marcadas por su pertenencia a la iglesia católica.

Vinculadas con estas diferencias, hubo mutuales más pequeñas y otras más numerosas. También la disposición de recursos económicos, el alcance y calidad de los socorros prestados, así como las conexiones con el medio social y político variaban ampliamente en estas sociedades. En tal

66 Al respecto, se pueden ver los artículos publicados por El Orden, durante los meses de agosto y setiembre de 1906. 
sentido, existieron sociedades que alcanzaron un mayor desarrollo en los servicios de salud y cobertura del sepelio, dispusieron de un capital físico más importante y lograron una proyección temporal más prolongada, tal como fue el caso de la Sociedad Argentina de Socorros Mutuos de Obreros.

Si bien la mayoría de las asociaciones mutuales pretendían cubrir los casos de enfermedad y fallecimiento, algunas incluyeron también dentro de los socorros otros rubros claves de la vida del trabajador y sus familias, al estipular mecanismos de colocación para los socios afectados por la falta de trabajo, como lo hicieron por ejemplo el Centro de Trabajadores de Monteros y sociedades de oficio como la Unión Tipográfica que estableció, además, ayudas para afrontar los casos de huelgas. En el caso de la asociación mutual de panaderos, junto con el respaldo a los trabajadores sin trabajo, para lo cual se preveía la solidaridad entre los asociados y la creación de agencias de colocación, se contempló también el caso específico de los trabajadores ambulantes.

Además de las diferencias en cuanto a la composición y al alcance de los socorros previstos, las mutuales difirieron también en el tipo de actividades que se proponían abarcar. En tal sentido, y si bien la ayuda mutua era su objetivo principal, las asociaciones mutuales persiguieron, además, otros propósitos que guardaban relación con el contexto de su surgimiento y el perfil social de sus integrantes, entre otros factores. ${ }^{67}$ Así, algunas mutuales buscaron, por ejemplo, fomentar la instrucción y cultura de los trabajadores a través de la fundación de un periódico y la creación de bibliotecas y salas de lectura. Una muestra en ese sentido se reflejó especialmente en las prácticas de la Sociedad Argentina de Socorros Mutuos de Obreros, el Centro de Trabajadores de Monteros, la sociedad Unión Tipográfica y el Centro Cosmopolita de Trabajadores.

Para atender aristas centrales de la vida de los trabajadores, concernientes a su sociabilidad, educación y cultura, otra consigna fundamental fue la organización de conferencias y la puesta en marcha de veladas y tertulias literario-musicales que aspiraban a estimular hábitos de moralidad, trabajo y educación en los trabajadores, al tiempo que les proporcionaban una alternativa consistente para el aprovechamiento del tiempo libre. Tanto la Sociedad Argentina de S.M. de Obreros, la Unión Tipográfica, los centros de obreros católicos y el Centro Cosmopolita de Trabajadores desplegaron, desde concepciones diferentes, actividades en ese sentido.

Para favorecer la educación y la cultura de los trabajadores, algunas de estas asociaciones de ayuda mutua se propusieron también dictar clases nocturnas y crear escuelas para los hijos de los asociados. Asimismo, el establecimiento de cajas de ahorro formó parte de la agenda prevista por

67 Al respecto, fueron iluminadores los trabajos de Hilda Sabato sobre las asociaciones en Argentina durante la segunda mitad del siglo XIX. En particular, SABATO, Hilda. 1860-1920, Estado y sociedad civil, p.99-167. 
las mutuales durante la época bajo estudio. En esa línea debemos destacar el caso de los centros católicos, en donde el socorro se combinaba con una preocupación central por el impulso a la educación enmarcada en los parámetros de la moralidad y la religión.

Los centros de obreros católicos, como ya se dijo en el trabajo, trascendieron sin duda el movimiento mutualista. Percibido el socorro mutuo como una de las estrategias encaminadas a estimular el adelanto de los obreros y atraerlos al ámbito de la iglesia, estos centros estipularon la ayuda mutua para los casos de enfermedad. Además, buscaron fomentar el trabajo mediante la creación de agencias de colocación, ofrecer alternativas para aprovechar el tiempo libre de los trabajadores y estimular su cultura y adelanto intelectual. De acuerdo con estas consignas, desarrollaron un extenso abanico de actividades que marcadas por las premisas de la moralidad y la defensa de la religión católica, combinaban el entretenimiento con la educación y la propaganda. Así organizaron a lo largo del periodo bajo estudio paseos y excusiones campestres, misas y conmemoraciones, conferencias, veladas musicales, comedias morales, etc.

Otro espacio que traspasó fuertemente el fenómeno del mutualismo fue el Centro Cosmopolita de Trabajadores, creado bajo la figura de la "protección mutua", pero que en realidad representó un verdadero espacio de impulso y coordinación que potenció las actividades de los trabajadores tucumanos, tanto aquellas de naturaleza mutual, como especialmente las referidas al terreno de la asociación gremial y la lucha obrera, la participación política y las manifestaciones de sociabilidad y cultura. En esa dirección, a través de este espacio obrero, sus integrantes, provenientes de un sector heterogéneo de trabajadores de oficio, militantes y dirigentes vinculados con el anarquismo y, sobre todo, con el socialismo, desarrollaron prácticas de disenso y de protesta frente a los patrones y los poderes públicos, intervinieron en la contienda electoral y compartieron eventos recreativos y culturales, tales como veladas y tertulias literario-musicales.

Ya para terminar, quisiera sugerir que las prácticas desarrolladas por los trabajadores a través de las sociedades de ayuda mutua podían contribuir al aprendizaje y al desarrollo de valores y comportamientos fincados en la solidaridad, el ahorro y el civismo; remitían también a la difusión de hábitos referidos a la discusión, la toma de decisiones, etc. Además, otra arista de las experiencias mutualistas se vinculaba con las tensiones y los conflictos relacionados con el manejo de los fondos económicos de la asociación. Sin duda ésta era una cuestión central de la vida asociativa que podía originar desacuerdos y peleas, alentando su difusión pública e incluso denuncias ante la justicia. Así, y aunque los dos juicios mencionados en el trabajo concluyeron con la absolución de los acusados, los mismos revelaron que los enfrentamientos internos también formaban parte de las prácticas mutuales en el mundo del trabajo de la época. 